\title{
Study on the Trading Partner Cultural Effects between Global Imports and Foreign Direct Investments in China
}

\author{
Guo Yu \\ College of Economics and Management \\ Shandong Xiehe University \\ Jinan, Shandong, China \\ Heye8511@sina.cn
}

\begin{abstract}
With the acceleration of globalization and blocking of the international economy, international trade and Foreign Direct Investments (FDI) take up the largest slice when it comes to the national economy. And recently, studies conducted on the effect of trading partner cultural effects and the relationship between global imports and Foreign Direct Investments (FDI) have been noticed. This paper, by means of Hofstede's cultural dimensions that reflects on the national cultural characteristics, studies how cultural differences affect the imports and Foreign Direct Investments (FDI) to China. At the same time, an empirical analysis of the impacts of Hofstede's five cultural dimensions on the relationship between Global Imports and Foreign Direct Investments (FDI) to China is also carried out. Imports and Foreign Direct Investments data of China from 2001 to 2017 is used for this study and regression analysis is based on the gravity model. This analysis strongly indicates that for China, the higher of the index of uncertainty avoidance, the more trade amount to China, while the less the Foreign Direct Investments (FDI). It shows that cultural factors affect largely the relationship between global imports and Foreign Direct Investments to China, and cultural differences accelerate the exchanges among Countries.
\end{abstract}

Keywords-National culture; Cultural differences; Foreign Direct Investments (FDI)

\section{INTRODUCTION}

As globalization and economic blockade deepen, the promotion of trade and foreign direct investment is being discussed as an effective national competitiveness measure. China is experiencing a rapid increase in trade and foreign direct investment due to the reform and opening economy that started in the 1980s. In 2017, China's imports amounted to US $\$ 19,592.3$ billion and FDI amounted to US \$ 195,602 million.

Culture can be expressed in various ways such as religion, language, values, norms, and traditions, and these play an important role in influencing interest groups, consumer preferences, and consumption behavior. According to previous studies, there are many studies on the effects of specific genetic factors such as language, religion, and race among various aspects of culture. In addition, many studies on the effects of cultural factors on international trade and foreign direct investment have revealed that cultural differences between countries have a positive effect on trade and foreign direct investment (FDI).
Therefore, this study intends to deeply examine the influence of cultural variables on mass exports and FDI by using cultural index of Hofstede, which reflects cultural characteristics of each country among various cultural factors. Through analytical researches, if five elements power distance, individualism, masculinity, uncertainty avoidance, long-term orientation are introduced respectively, from the results, if power distance and uncertainty avoidance decreases, the Imports to china reduces as well, but Foreign Direct Investments (FDI) to China grows. If the long-term orientation decreases, we get an opposite results.

\section{LITERATURE REVIEW}

There are various studies on the effects of cultural differences in each country as important variables among factors affecting exports and FDI for China. This study used 17 years of data from 2001 to 2017 for empirical analysis to examine the effects of the global top 30 exports (including China) on mass exports and FDI in 2015. The main variables are trade, the share of export investment defined as the sum of mass exports and direct investments in each country, the real GDP of each country, GDP per capita, the distances between the two countries (Dist), and cultural differences between the two countries $(\mathrm{Cul})$. Using the variables, we set up a new model based on the gravity model, which is the most representative empirical analysis model to explain the international trade pattern, and conducted a regression analysis.

\section{A. Culture dimension and export}

Various studies have been conducted on the effects of cultural factors on international trade. Language, and religion cannot be denied as a factor representing the national culture, but it is a specific part of the various cultural factors that the state has. It is difficult to reflect each specific factor into the overall culture of the nation. Based on these limitations, studies that quantify cultural characteristics are also being conducted at the same time. And in some studies, the index of cultural characteristics is used to reveal the relationship between international trade and culture. A typical example of this is Hofstede's cultural indicators.

Bruce Kogut and Harbir Singh (1988), differences in the trends of countries in the selection of modes of entry into foreign markets are explained by the differences of cultures between countries. In this study, Kogut and Singh index, 
which is calculated based on Hofstede's cultural indicators of four dimensions, is presented as a cultural distance measurement method.

Kogut and Singh (1988) based on the Hofstede index, which has been widely used in international business studies such as Loree and Guisinger (1995), Barkema and Vermeulen (1997), Park and Ungson (1997) and Brouthers and Brouthers) It used to measure cultural distance. As a result, institutional distance has a negative effect on bilateral trade, and cultural distance and institutional quality have a positive effect on bilateral trade.

In Rongxing Guo (2004), two cultural factors, language and religion, analyze the effects of trade on the US and China. We conclude that cultural similarity measured by language and religion has a greater impact on Chinese trade than in the United States.

Gert-Jan M. Linders, Arjen Slangen, Henri L. F. de Groot and Sjoerd Beugelsdijk (2005), cultural and institutional factors play a determinant role in bilateral trade flows. In 1999, we analyzed the bilateral export volume among 92 countries in the world using simple OLS based on the gravity model and a random effect model of the panel data.

Meijers (2010) analyzed the impact of the Internet on economic growth using data from a total of 167 countries from 1998 to 2008. The results show that the Internet has no direct effect on economic growth but has a significant effect on indirect economic growth owing to trade facilitation. Also, the higher the openness, the higher the effect of internet on trade. Overall, we can see that the Internet has a positive effect on international trade.

\section{B. Culture dimension and FDI}

It is no exaggeration to say that the world is now in an age of infinite competition. Companies as well as countries are competing for their continued growth. The rapid development of information and communication technologies, such as the Internet and multimedia, and the rapid development of transportation have connected the entire world with one network. In economic activities, the border of individual countries is eliminated and a single market is formed as a single market. Under such a competitive structure, companies are focusing on strategies for localization of local consumers as well as globalization strategies. In addition, since foreigners and their families living in the local area need to live in their own country, it is a reality that most of them are pointed out as difficulties for their dispatch workers and their families because they need their children's school, cultural life, hotel, English use and foreign medical facilities .

Devereux and Griffith (1998) suggested that cultural factors include local law, language, religion, racial issues, employee education levels, and union attitudes.

Hofstede (2001) defined culture as "mental programming of human mind". Ethical (cultural) differences that may vary from country to country, such as product stability, the use of recycled raw materials, and the definition of labor force, may determine the success and failure of multinational corporations.
Fletcher and Brown (2005) argue that time, space, language, familiarity, consumption patterns, and business customs are very important for major cultural differences.

Florida (2007) stated that what is needed for sustainable economic development is the optimal use of creativity and that there is a formula called 'three T's' for economic development for the next generation's prosperity. This is a study that the cultural elements of a country can be an important factor when a company goes abroad.

\section{RESEARCH MODEL}

This study adopts a gravity model to analyze the impact of national culture on public exports and FDI. The gravity model uses the concept of gravity to interpret and interpret analogies of trade volume, flow of capital and immigration among countries. The gravity model is derived from the Newton's Law, which measures the gravity (GFij) between objects i and $\mathrm{j}$.

Newton's law of universal gravitation can be briefly explained as follows. The force of attraction of two objects to each other is proportional to the product of the masses of two objects and is inversely proportional to the square of the distance. The gravity model, first introduced by Tinbergen (1962), draws conclusions from the empirical analysis of international trade, although it is a relatively simple form, proportional to the size of the economies of both countries and inversely proportional to distance.

The gravity model is evaluated not only for the flow of trade between countries but also for FDI flow analysis. First, the GDP of the investment target country, which is a key variable of the gravity model, has a positive effect on the FDI decision as a key factor of the location advantage represented by the market potential. On the other hand, geographical distance, another key variable of the gravity model, negatively affects FDI decisions caused by transaction costs and management costs.

The purpose of this study is to investigate the effect of public foreign direct investment versus mass exports on the main variables and cultural variables which are influential on export and direct investment as independent variables.

$$
\begin{aligned}
& \begin{array}{c}
\frac{F D I_{i t}}{E X_{i t}}=C+\frac{F D I_{i t}-1}{E X_{i t}-1}+G D P_{i t}+P G D P_{i t}+D_{i s t}+U A \\
+P D+C I+M F+L S+\varepsilon
\end{array} \\
& \begin{aligned}
\frac{F D I_{i t}-3}{E X_{i t}}=C+ & \frac{F D I_{i t}-4}{E X_{i t}-1}+G D P_{i t}+P G D P_{i t}+D_{i s t}+U A \\
& +P D+C I+M F+L S+\varepsilon
\end{aligned}
\end{aligned}
$$

This study conducted an empirical analysis using public export and FDI data of 29 countries from 2001 to 2017 for 17 years. Data were collected from the International Monetary Fund (IMF), World Trade Organization (WTO), Statistics Bureau of China, Statistics Bureau of Taiwan, and the Institute of International Economics of France. Among them, Hong Kong and Taiwan are considered to be special areas due to the specificity of regional economic system.

The modified R-square of the explanatory variable is explained as $68 \%$, and the explanatory power of the model is 
high. The proportion of direct investment and exports of t-1 was analyzed by the influence of positive (+) and significant level of $99 \%$. The GDP variable was analyzed as the positive (+) effect and the significance level was 99\%. The per capita income variable was analyzed as the effect of positive (+), but it was not significant. The geographical distance variable between countries was analyzed by the negative (-) effect, and the significance level was $99 \%$. At the cultural level, the uncertainty avoidance variable was analyzed by the negative (-) effect and the significance level was $99 \%$. The power distance variable was analyzed by the negative (-) effect and the significance level was $99 \%$. Individualism variables were analyzed by positive (+) influence. Significance level of $90 \%$. The male variables were analyzed by the negative effect. Significance level of $90 \%$. The long - term directional variables were analyzed by the positive $(+)$ effect. Significance level of $99 \%$.

TABLE I REGRESSION ANALYSIS OF MODEL 1

\begin{tabular}{|c|c|c|c|c|c|c|c|}
\hline $\begin{array}{l}\text { Dependent } \\
\text { variable }\end{array}$ & Independent variable & $\mathrm{R} 2$ & $\Delta \mathrm{R} 2$ & $\mathrm{~F}$ & B & $\beta$ & $\mathrm{T}$ \\
\hline \multirow{10}{*}{$\begin{array}{l}\text { FDIit/ } \\
\text { EXit } \\
(\ln )\end{array}$} & constant & \multirow{10}{*}{.634} & \multirow{10}{*}{.628} & \multirow{10}{*}{$93.139 * * *$} & .822 & & $23.757 * * *$ \\
\hline & FDIit-1/EXit-1 & & & & .103 & .430 & $14.199 * * *$ \\
\hline & GDPit & & & & .069 & .129 & $4.124 * * *$ \\
\hline & PGDPit & & & & .006 & .077 & 1.927 \\
\hline & Dist & & & & -.066 & -.166 & $-4.349 * * *$ \\
\hline & UA & & & & -.002 & -.265 & $-7.793 * * *$ \\
\hline & PD & & & & -.002 & -.231 & $-5.595 * * *$ \\
\hline & $\mathrm{CI}$ & & & & .001 & .106 & $2.331 *$ \\
\hline & $\mathrm{MF}$ & & & & .000 & -.062 & $-2.083 *$ \\
\hline & LS & & & & .002 & .270 & $7.262 * * *$ \\
\hline
\end{tabular}

The modified R-square of the explanatory variable is explained as $61.4 \%$ and the explanatory power of the model is high. The proportion of direct investment and exports of t-4 was analyzed by the influence of positive $(+)$ and significance level was $99 \%$. The GDP variable was analyzed as the positive (+) effect and the significance level was $99 \%$. The per capita income variable was analyzed by the positive $(+)$ effect and the significance level was found to be $95 \%$. The geographical distance variable between countries was analyzed by the negative (-) effect, and the significance level was $99 \%$. At the cultural level, the uncertainty avoidance variable was analyzed by the negative (-) effect and the significance level was $99 \%$. The power distance variable was analyzed by the negative (-) effect and the significance level was $99 \%$. Individualist variables were analyzed by positive $(+)$ effect, and significance level was $90 \%$. The male variables were analyzed by the negative (-) effect and the significance level was 90\%. The long - term directional variables were analyzed by the positive (+) effect and the significance level was $99 \%$.

\section{CONCLUSION}

This study analyzed the effect of culture on mass exports and direct investment. As the development of world trade, the cultural characteristics of the country, not only in China but also in the whole world, are directly or indirectly affecting between exports and direct investment.

TABLE II REGRESSION ANALYSIS OF MODEL 2

\begin{tabular}{|c|c|c|c|c|c|c|c|}
\hline $\begin{array}{l}\text { Dependent } \\
\text { variable }\end{array}$ & Independent variable & $\mathrm{R} 2$ & $\Delta \mathrm{R} 2$ & $\mathrm{~F}$ & $\mathrm{~B}$ & $\beta$ & $\mathrm{T}$ \\
\hline \multirow{10}{*}{$\begin{array}{l}\text { FDIit-3 } \\
\text { /EXit } \\
\text { (ln) }\end{array}$} & constant & \multirow{10}{*}{.622} & \multirow{10}{*}{.614} & \multirow{10}{*}{$77.796 * * *$} & .796 & & $20.055 * * *$ \\
\hline & FDIit-4/EXit-1 & & & & .148 & .384 & $11.669 * * *$ \\
\hline & GDPit & & & & .090 & .164 & $4.853 * * *$ \\
\hline & PGDPit & & & & .010 & .123 & $2.800 * *$ \\
\hline & Dist & & & & -.081 & -.190 & $-4.602 * * *$ \\
\hline & UA & & & & -.002 & -.252 & $-6.813 * * *$ \\
\hline & $\mathrm{PD}$ & & & & -.001 & -.208 & $-4.631 * * *$ \\
\hline & $\mathrm{CI}$ & & & & .001 & .099 & $1.995 *$ \\
\hline & MF & & & & -.001 & -.074 & $-2.279 *$ \\
\hline & $\mathrm{LS}$ & & & & .002 & .267 & $6.635 * * *$ \\
\hline
\end{tabular}


From 1998 to 2014, there is a limit to the study of China's export and direct investment data to analyze the impact on China's overall exports.

Also, Hofstede's cultural indicators, which are used as the main framework of analysis, do not seem to reflect all the various aspects of culture, so we would like to utilize diverse cultural indicators such as GLOBE for future research. Finally, it is necessary to examine the trends in the analysis of 29 countries and China only, and expanding the regions of South America, East Asia, Middle East and Africa to analyze them.

\section{REFERENCE}

[1] Hofstede,G.(2001), Culture`s consequences: Comparing values, behaviors, institutions, and organizations across nations,(2nd ed.) Beverly Hills, CA: Sage.

[2] Harry G. Barkema and Freek Vermeulen (1997), "What Differences in the Cultural Backgrounds of Partners Are Detrimental for International Joint Ventures? ", Journal of International Business Studies, Vol.28.

[3] Swenson, D. L.(1993), "Foreign mergers and acquisitions in the United States", Foreign direct investment. University of Chicago Press. pp255-284

[4] Kingsley O. Olibe and C. Larry Crumbley (1997), "Determinants of US Private Foreign Direct Investments in OPEC Nations: From Public and Non-public Policy Perspectives", J. of Public Budgeting, Accounting \& Financial Management, 9(2), pp331-355. 